off with sharp pecks. Rails can run up the rushes also, clinging there with the help of their hind toes on the swaying stem, and get seeds, insects or berries at the top. Their long, front toes, flattened but scarcely lobed, enable them to tread out a dinner from the mud. Beetles, small crustaceans and small forms of water invertebrates as well as grasshoppers, are favourite foods.

The nest was built on a mound of cattail stems and grasses, on the ground at the marshy, muddy, sodden edge of the water. It was well hidden among tall cattails and wild willows. It seemed almost to have a dome or kind of cover and was full of eggs. The eggs were pale, creamy white, speckled with brown.

It was easy to get a picture of the nest, but I did worry that I might cause the female to desert. The male came when she called but stayed well out of range and was very secretive.

Rails' meat was (maybe still is) considered a delicate, gourmet food. Such a pitifully small, thin body re- quired the cooks to pluck dozens for one meal, thus the expression "thin as a rail."

Rails make only short, weak flights on seemingly feeble wings, yet they may migrate from the West Indies to Hudson Bay. So their flight is not at all as feeble as it appears to be.

I wonder if the pair will return to the same spot for the third year. They did have a successful hatch. I wonder if I will have better luck getting a picture.

Maybe I should try a blind - but maybe not, we don't want them to abandon that perfect nesting site. Maybe I should take along a pocket comb to attract the rails, as scratching the teeth of a comb produces a sound like the rail's call. Maybe that would bring one close.

I am much intrigued with these small, shy birds. They are more often heard than seen. They are so seldom seen that they are virtually unknown. Very few articles and good photographs have appeared in publications.

\title{
EXTRAVAGANT NEST DEFENSE - UNLIKELY TO PAY OFF
}

\begin{abstract}
A. J. (TONY) ERSKINE, Canadian Wildlife Service, Box 1590, Sackville, New Brunswick. EOA $3 \mathrm{CO}$
\end{abstract}

Defense of nests or broods is potentially risky, exposing the parent bird as well as its eggs or young to a predator. When defense is prolonged in time or space or both, it risks attracting other predators besides the one that set off the reaction. If such behaviour occurs in most individuals of a species, we infer that benefits of defense outweigh the costs. With species in which nest defense is not usual, such behaviour may be no more than individual aberration. 
Breeding shorebirds, especially sandpipers such as Greater and Lesser Yellowlegs, are examples of species that habitually and persistently protest human intrusions in their nesting areas. ${ }^{1,2}$ Gulls and terns defend their nests and young aggressively against humans as well as other animals. Many other examples could be cited.

Ducks, especially dabbling ducks, are well known for "distraction displays" when their broods are approached by people on land as well as on water. Nest defense, however, is not characteristic of ducks and would not be expected, given their relatively clumsy movement on land. In my experience, a duck on its nest usually relies on concealment in vegetation until the last moment. It then departs conspicuously, often quacking while fluttering low over the ground, sometimes for $200 \mathrm{~m}$ or more, in an attempt to distract the predator away from the nest. Two Mallard females that I encountered nesting on my study plots near Mafeking, Manitoba, in 1972 behaved in this typical manner, but a female Ring-necked Duck there provided an aberrant exception.

Most Ring-necked Ducks nest in shrubby marshes, close to or over open water, as these diving ducks are less agile on land than Mallards. The study plot was in the shrubby zone fringing a boggy impoundment, with no obvious surface water nearer than 300-400 m. ${ }^{3}$ On 1 July 1972, at 5:55 a.m., I flushed a female Ringnecked Duck from an incomplete clutch ( 6 eggs, no down) in an open sedge area, $50 \pm \mathrm{cm}$ from a marked line I had followed on 8 surveys over the previous 5 weeks. On that visit, and again on 5 July (9:05 a.m.; 8 eggs, little down), the duck flew away normally, with considerable commo- tion. My final visit, during a survey of the plot's vegetation on 8 July, produced the following different response [slightly expanded from my field notes]. When I was $1.5 \pm \mathrm{m}$ from the nest, the duck came off, flapping around my feet as if feigning near a brood. As I moved closer, she beat up against my waders. I caught her by hand, checked her legs for bands (none) - as I wondered if such unusual behaviour indicated a captive-reared bird familiar with people. Then I tossed her into the air. Instead of flying away, she came down immediately and, as 1 bent over to count the eggs (still 8, little down), she rushed onto the nest and covered it, and then moved out at me aggressively. As I moved away, she returned to the nest "like a broody hen." I did not revisit the plot later.

If such a response had been made to a mammalian predator, that duck would not have survived to bring off her nest. Her activity, except when I tossed her into the air, was on the ground, so it need not have attracted other predators. It is conceivable that the duck, "remembering" from earlier visits that I had not then been distracted by her conspicuous departures, was trying a different defense. However, I cannot imagine such behaviour providing any benefit either to the present clutch or to the lifetime reproduction of the parent. Its apparent success in defending its nest against me is unlikely to have been a helpful precedent. Such behaviour is not "for the birds," but works against them.

1. ERSKINE, A.J. 1968. Birds observed in north-central Alberta, summer 1964. Blue Jay 26:24-31.

2. - 1974. Off into the wet green yonder: birds and plants of a boreal bog. Blue Jay 32:33-37.

3. 1968. Shrubby marsh. Am. Birds 26:992-993. 